\title{
Regime Type and International Conflict: Towards a general model
}

\author{
Benjamin E. Goldsmith \\ Department of Politics \& International Relations \\ Macquarie University \\ Stephan K. Chalup \\ Michael J. Quinlan \\ School of Electrical Engineering \& Computer Science \\ University of Newcastle, Australia
}

Abstract: The authors take a new look at the relationship between regime type and deadly militarized conflict among pairs of states (dyads) in the international system. With the goal of describing the general functional form, they evaluate three perspectives: democratic peace, regime similarity, and regime rationality. They employ both standard logistic regression (logit) and a recently developed machine learning technique, a support vector machine (SVM). Logit is dependent on assumptions which limit flexibility and make it difficult to discern the appropriate functional form. SVM estimation, on the other hand, is highly flexible and appears capable of discovering a relationship that is contingent on other variables in the model. SVM results indicate that regime similarity and joint democracy are important in most dyadic interactions. However, for the special but important case of the most dangerous dyads, regime rationality plays a role and the democratic peace effect is dominant. The results suggest that models of international conflict excluding distinct indicators for political similarity, joint democracy, and joint autocracy may be misspecified. SVMs are an especially useful complement to conventional statistical methods.

Acknowledgements We thank Paul Hensel, Yusaku Horiuchi and participants in a Newcastle School of Policy research seminar and a 2006 International Studies Association panel 
for valuable comments. Goldsmith gratefully acknowledges support under a University of Newcastle New Staff Grant. The data used in this article can be found at http://www.prio.no/jpr/datasets. Please direct correspondence to ben.goldsmith@mq.edu.au. 
This article uses a new method to investigate an important question in the study of war and peace: what is the relationship between domestic political systems and international conflict? We concur with Beck, King, \& Zeng (2000: 22) that empirical studies have produced some inconsistent results, apparently sensitive to model specification and methodological choices. This lack of robustness is likely due to the complex, contingent, and 'massively interactive' nature of international relations.

Assumptions in common statistical methods, such as logit, impose potentially inappropriate constraints and can produce misleading, even if statistically significant, results. The problem can also be seen as one of underspecified theory. If the functional form of the relationship between regime type and conflict were more finely and definitively hypothesized, standard methods might be used with the appropriate data transformations and interactions.

In order to move towards a more general understanding of the relationship (functional form) between regime type and conflict, we take a similar approach to that of Beck, King, \& Zeng $(2000 ; 2004)$, who suggested using a machine learning technique called artificial neural networks (ANNs). Our study differs from theirs in several important ways: first, we specifically focus on the regime type variable rather than broad methodological issues; second, we employ a newer and more efficient machine learning technique, support vector machines (Boser, Guyon, \& Vapnik, 1992; Cortes \& Vapnik, 1995; Vapnik, 1995); third, we use a more appropriate set of control variables based on common practice in the field of international relations.

The article proceeds as follows. First we discuss three theoretical perspectives on the relationship between regime type and conflict. Next, we deal with specification issues regarding indicators for dyadic regime type, the key independent variable. Subsequent sections discuss, 
respectively, the data, SVM and logit methods, and the results of our analyses. We show the sensitivity of logit to model specification, then focus on the functional form suggested by SVM estimation. Our findings allow us to integrate the effects of regime similarity, regime rationality, and democratic peace to tell a coherent story about when each perspective is most relevant based on the prior likelihood of conflict. Our preferred models have considerable out-of-sample predictive ability.

\section{Theories about Regime Type and Conflict}

The most common approach to theorizing about regime type and international conflict is the democratic peace. Authors have advanced both normative and structural theories to explain why conflict, escalation, and war are less likely when two democracies interact (e.g., Maoz \& Russett, 1993). Normative explanations focus on elite-level practices of compromise and non-violent conflict resolution. Policy makers, socialized into such domestic practices, will expect similar behavior in the international realm when dealing with leaders from other democracies. Structural or institutional explanations focus on constraints placed on leaders such as mass suffrage or separation of powers. Both the normative (e.g., Cederman \& Rao, 2001; Dixon, 1994) and the

structural (e.g., Bueno de Mesquita et al, 1999; Lake, 1992) explanations are rich literatures, but the purpose here is only to illustrate the core, shared empirical expectation of a lower likelihood of conflict for democratic dyads.

These constructs for the democratic peace can lead to either a categorical or an interval implication for empirical studies, depending on whether they predict that incremental rises in 'democraticness' imply incrementally higher likelihoods of peace. It is often not clear from theory how general the expected effect is. A categorical effect would simply distinguish 
democratic from other dyads ('democracies don't fight each other'), but an incremental effect would imply general tendencies across all regime types. Figure 1 displays the hypothetical functional forms, plotting the predicted outcome (the probability conflict) on the $\mathrm{z}$ axis using a 3 way surface graph, with each dyad member's regime type along the $\mathrm{x}$ and $\mathrm{y}$ axes (1(a) categorical, 1(b) incremental).

\section{Figure 1 here}

But the democratic peace proposition and its empirical support can be qualified from at least two directions. First, it is possible to argue that regime similarity (or political distance) rather than joint democracy accounts for the empirical regularities, either in whole or in part. ${ }^{1}$ Werner (2000) has presented theoretical arguments and empirical support for this perspective. She focuses on the sources of conflict, rather than the conflict-inhibiting factors emphasized by democratic peace theorists.

Werner suggests that the issues at stake in international conflict have their roots in the 'management of domestic affairs.' These can be divided into 1) concerns about 'the treatment of individuals within states' and 2) issues connected with 'the composition of a state's government.' First, democracies are expected to be interventionist when issues of human rights or treatment of minorities are at stake. The target will most often be illiberal states. Illiberal states will not threaten each other in this way, but may fear liberal interventionist behavior, and use force to cut

\footnotetext{
${ }^{1}$. Werner includes lower democracy but recognizes that this weak-link indicator makes it 'difficult to differentiate the effects of similarity from the effects of democracy' (2000:368). A strong interpretation of her results is that political similarity has a pacific effect, but the effect of joint democracy remains uncertain.
} 
ties between liberal states and potential pockets of domestic opposition. Second, domestic institutions may shape or be perceived to shape foreign policy preferences, and thus regime differences may become a concern for leaders. Leaders also may be concerned about the effect of other states' political systems on their own hold on power (e.g., 'contagion' effects); or leaders may see domestic institutions in other states as harming their state's interests, for example by creating trade barriers (Werner, 2000: 343, 346-48). Thus, the closer any two regimes are to each other in type, the less likely conflict (Figure 1(c) presents the hypothesized functional form). ${ }^{2}$

Other studies provide related arguments and evidence. Beck, King, \& Zeng (2004) suggest that regime similarity is a plausible alternative to democratic peace. Peceny, Beer, \& Sanchez-Terry (2002) argue that personalist dictatorships and single-party (socialist) states are less likely to come into conflict with each other. Mousseau (1998) finds that regime similarity positively affects the ability of states to resolve disputes through compromise. Lai \& Reiter (2000) find that regime similarity, and not joint democracy, positively affects the likelihood of states cooperating through a military alliance.

A second important set of arguments providing qualifications to theories of democratic peace is the 'bargaining' approach, which puts the causal emphasis on strategic choices made by rational state leaders as information is revealed through crisis signaling (Fearon, 1994; Reiter, 2003). Arguing that the outcomes of strategic interactions are subject to selection effects and non-linear dynamics, Signorino (1999; 2003; Signorino \& Yilmaz, 2003) in particular critiques common statistical models of international conflict.

\footnotetext{
${ }^{2}$. To the extent regime type and foreign policy preferences are related, Werner's argument overlaps with preferencebased arguments (e.g., Gartzke, 1998). If there is a close empirical relationship between regime type and preferences, we suspect regime type is the causal variable (i.e., foreign policy preferences do not typically cause a state to have a certain regime type).
} 
In the bargaining approach, much depends on whether states send credible signals or give in to the temptation of bluffing. Fearon (1997) argues that 'bluffing' - a leader making a threat or commitment that s/he does not intend to follow through on - seems to occur more often than the logic of bargaining models would warrant. Below we explain how our interpretation and extension of this literature leads to the following conjectures: 1) democracies will tend not to bluff, and thus jointly avert war through credible signaling; 2) autocracies will tend to bluff, but will be able to retreat from bluffs due to relatively low audience costs, averting war with each other; but, 3) anocracies will tend to bluff while being unable to later retreat from their positions, thus stumbling into wars, even when defeat is likely.

This is a complex literature, but there are at least two central features. First, rational leaders pursuing the national interest with accurate information should never prefer war, given that the state likely to lose will be better off conceding some value in a pre-war bargain. Second, each state has private information the other requires, so in order to make such bargains likely states need to credibly calibrate the signals they send with their actual preferences. Since there are strategic incentives for bluffing, this becomes difficult. The focus has been on the ways that democratic institutions allow for credible signaling by imposing audience costs for bluffing (e.g., Schultz, 1999).

However, a plausible extension of this literature can be based on the idea that leaders in fully authoritarian states face a double-edged effect of the lack of significant audience costs. Because by definition authoritarian leaders are least reliant on social support to maintain power, audience costs are small ${ }^{3}$ and can be further ameliorated through control of information within

\footnotetext{
${ }^{3}$. Whatever audience costs may be incurred among a small 'selectorate' are assumed to be addressable by sidepayments (Bueno de Mesquita et al., 1999).
} 
the domestic realm (there is no free press). This allows authoritarian leaders a freer hand in signaling behavior. As the bargaining literature makes clear, it also reduces the credibility of signals, and thus their effectiveness as tools of rational bargaining. But we point out that this also is based on very low costs for backing down (rescinding a bluff) for authoritarian leaders.

Thus we argue that a regime rationality perspective expects both authoritarian and democratic regimes will enjoy some degree of separate peace. When a bluff has been called by another country (through a credible move towards war), leaders of fully authoritarian states, facing few serious internal challenges to their rule, will not need to please any sub-state group to the detriment of state-level vital interests. They will go to war only if it promises gains for the state, which they in effect own. If war will bring losses for the state, rational authoritarians will choose to back down. Leaders of fully democratic states will be discouraged from acting on the temptation to bluff by the knowledge that backing down will incur audience costs. They will in effect be constrained in this way from bias toward sub-national groups because the audience is the whole society (Fearon, 1998: 310), meaning that resolve for war will only exist when society as a whole would be better off.

But leaders of all other regimes, which allow for some degree of authoritarian rule within a context of partially open contestation for power, will have incentives to pursue policies biased towards the sub-state groups which can facilitate access to power. This 'pathological' domestic political bias leads to sub-optimal foreign policies (Fearon, 1995: 409). Leaders in such states may be domestically compelled to exaggerate resolve through bluffing. Foreign leaders may realize that carrying through on such bluffs would not be rational for the state; but, importantly, anocratic leaders may be trapped into using appeals such as belligerent nationalism to gain internal support. If one leader does not adopt such an approach, the imperfect institutions of 
political competition allow another leader to replace him, for example through a coup to "save the nation' from an exaggerated foreign threat. If there is a sub-national group which would benefit from war more than peace, then the leader in an anocracy will have an incentive to bluff in crises, but then will also encounter a domestic imperative not to walk away. What is intended as a bluff at the time may become a self-fulfilling prophecy. This dynamic can lead to policies such as belligerent, outwardly-directed nationalist rhetoric or the privileging of a militarized foreign policy (Reiter, 2003: 36). Anocratic leaders will tend to paint themselves into a corner and be unable to pay the cost of walking away (losing power domestically), thus stumbling into war. The anocratic regime may thus behave irrationally from the perspective of state-level interests, but rationally from the perspective of the leader seeking to maintain power.

To illustrate these three conflict dynamics, we briefly point to examples from Latin American conflicts. An example of regime 'irrationality' in an anocratic dyad is the 1969 Football War between Honduras and El Salvador (polity scores of -1 and 0 , respectively). Honduras's Lopez Arellano stumbled into a losing war with a stronger state after using belligerent policies to maintain domestic power. An example of autocratic rationality is the 1978 Beagle Channel dispute between Chile and Argentina (polity scores -7 and -9 , respectively). Faced with Chilean resolve in a tense Naval confrontation, Argentina's military junta was able to back down from its challenge over three islands, with little apparent cost. Examples of democratic dyads which did not allow disputes to escalate, as expected with credible signaling, are Costa Rica and Nicaragua (polity scores 10 and 8 , respectively), which were able to prevent militarized disputes in 1995 and 1998 from escalating to more serious conflict, and the Venezuela-Colombia dyad, fully democratic from 1968 to 2000, which experienced eight MIDyears over issues including contested off-shore oil resources, but no deadly disputes. 
The bargaining literature also indicates that mixed dyads will be subject to miscommunication and thus more likely to go to war. Democracies may fear exploitation by authoritarian regimes, and authoritarian regimes may believe democracies lack war-fighting resolve, leading to conflict (Reiter 2003: 35-36). Fearon (1997: 83) points out that basic institutional differences can make certain types of signals, 'sunk costs', more likely for authoritarian leaders, while democratic leaders are more likely to use 'tying hands' signals, increasing the chances for misperception of resolve.

Therefore democratic dyads and authoritarian dyads should rationally avoid war to a greater extent, while mixed or jointly anocratic dyads should not. The hypothesized form of this relationship is represented in Figure 1(d). Empirical results consistent with some degree of autocratic peace complementing the democratic peace include Gleditsch \& Hegre (1997) and Maoz \& Abdolali (1989).

While each of these perspectives - democratic peace, regime similarity, and regime rationality - is consistent with the finding that fully democratic dyads have a very low probability of war, they also make different predictions regarding regime type for dyads which are not jointly democratic. For evaluation using conventional statistical methods, therefore, it is important to construct measures of dyadic regime type which capture the full range of possible pairings.

\section{Variable Specification}

Problems with weak-link indicators

Much of the democratic peace literature has relied on a 'weak-link' indicator of joint democracy based on the least democratic state in each dyad (Dixon, 1994). Sometimes a mirror-image 
measure of the highest democracy score is included as a control for regime similarity (Reuveny \& Li, 2003; Russett, Oneal, \& Davis, 1998). We do not believe these are the most appropriate indicators for studying dyadic regime type.

In particular, we believe that joint democracy and regime similarity are conceptually distinguishable, whereas the weak-link approach confounds them. It is of course true that jointly democratic dyads comprise a subset of dyads with similar regimes. But regime-similarity theories such as Werner's apply across the full range of possible dyadic combinations, and are logically independent of the democratic peace proposition.

In most studies the weak-link measure for any given dyad uses the lower of the two states' democracy scores on the standard Polity index (Marshall \& Jaggers, 2002). This ranges from -10 to +10 for fully authoritarian and fully democratic states, respectively. The measure is precise about one aspect of joint democracy: whether both states are of the highest degree of democracy, +10 . When the lower democracy score is +10 , then it is certain that the 'higher' democracy score of a dyad is also +10 . Similarly, when the lower democracy score reaches the standard threshold of +7 , we can still be sure that the higher democracy score is at least +7 and the dyad is 'democratic'. But there is less precision. The higher score could take any value from +7 through +10 . The lower democracy score gives only limited information about the dyadic level of democracy because the higher democracy score is only known to be greater than (or equal to) the lower score.

This imprecision becomes problematic because it conflates the concept of "joint democracy' with that of political distance. With lower democracy scores of +7 or higher (joint democracy), the distance between the score of the two dyad members can never be more than three points. But, with for example a lower democracy score of +5 , the other member of the dyad 
might be fully democratic $(+10)$ or also non-democratic $(+5)$. The noise, and average distance, thus increase as the lower democracy score decreases, so that a lower democracy score of -10 allows the other dyad member to take any value $(-10$ through +10$)$. This is a noisy and biased indicator of political distance, but it is a measure of political distance as well as joint democracy. The correlation between the lower democracy score and political distance is fairly strong $(r=$ $.50)$.

Including the higher democracy score in multivariate analyses does not rectify the situation. The higher democracy score simply provides a mirror-image measure to the lowerdemocracy score; it could be called the 'lower autocracy' score. A value of -10 indicates with certainty that the dyad is fully authoritarian, while a value of +10 would include dyads with the other value ranging from -10 to +10 . There is the same confounding of joint regime type and political distance, but in the opposite direction $(r=.48)$. It is arbitrary and mathematically meaningless to designate one as representing regime type and the other as representing political distance.

\section{Alternative indicators of regime type}

In order to deal with this problem in logit analyses we employ some alternative indicators. The first is a simple dummy variable for joint democracy, coded ' 1 ' if both dyad members are democratic (the hypothesized functional form in Figure 1(a)). The cut-off of ' +7 ' or higher is widely used, and recommended in the Polity IV documentation. We designed another indicator which reflects the idea that there are degrees of joint democracy. This conforms to the idea that 'the more democratic each member of the dyad, the less likely is conflict' (Maoz \& Russett, 1993: 633). Our interval measure of joint democracy is a 12-point scale (0-11) which captures 
both the polity score for each state in the dyad and whether one, both, or neither state in the dyad is democratic, or partially democratic (Table A; functional form in Figure 1(b)). While closely related to the weak-link lower democracy indicator $(r=.89)$, importantly, it is not highly correlated with political distance $(r=-.10)$. Full details are found in the appendix, but for example a rank of 11 is given to a dyad in which both states have Polity scores of +10 , while a rank of 10 is given if one state has a score of +10 while the other is +7 through +9 ; dyads with one democracy are ranked higher than dyads without a democracy, descending to completely authoritarian dyads, which rank " 0 ".

We have also used several approaches to measuring regime similarity. One approach uses three dummy variables coded ' 1 ' when both dyad members share a regime type, either democracy $(+7$ through +10$)$, anocracy $(-2$ through +2$),{ }^{4}$ or authoritarianism $(-10$ through -7$)$. Another approach more directly measures 'political distance' and ranges from ' 0 ' for dyads in which both states have identical scores to ' 20 ' for dyad members that are as far apart as possible on the Polity scale, i.e., political distance $=\mid$ StateA-StateB $\mid$. This functional form is pictured in Figure $1(\mathrm{c})$. In addition, we use a categorical regime similarity variable coded ' 0 ' if political distance is 4 or greater, and ' 1 ' if it is 3 or less (to test whether the $0-20$ interval indicator's performance in models is due to its more finely grained scale).

Our logit models using this battery of indicators demonstrate sensitivity to the choice of indicator (functional form). We find plausible, statistically significant models to support and refute each of the hypothesized relationships: democratic peace, regime similarity, and regime

\footnotetext{
${ }^{4}$ We recognize that there are other possible ways to code joint anocracy. We feel this is the most appropriate to capture political similarity. Models including all dyads jointly in the range of -6 to +6 , and finer distinctions $(-6$ to $3,-2$ to $+2,+3$ to +6 ) did not produce significant results. We thank two anonymous referees for drawing our attention to this issue.
} 
rationality. How does one choose between these models? Our central argument is that machine learning techniques provide tools for informed choice. With the guidance of theory and plausible statistical results, the support vector machine can estimate the most likely functional form of the relationship of interest, while accounting for potentially massive complexity in the data. ${ }^{5}$

\section{Methods}

\section{Logit and SVMS}

Here we briefly discuss logit and SVM methods. Logit estimation is commonly used in quantitative studies of international conflict involving binary dependent variables, usually coded ' 1 ' for instances of international conflict, ' 0 ' otherwise. The logit equation can be represented as the probability of an outcome $y_{i}$ conditioned on input(s) $x_{i}$,

$$
\operatorname{Pr}\left(y_{i} \neq 0 \mid x_{i}\right)=\frac{\exp \left(x_{i} \beta\right)}{1+\exp \left(x_{i} \beta\right)}
$$

where $y_{i}$ is a binary vector representing the onset of fatal conflict, ' 1 ', or peace ' 0 ', for dyads $i=$ $1, \ldots, \mathrm{n} ; x_{i}$ is a vector of independent variables representing regime type and other factors hypothesized to affect the likelihood of conflict, and $\beta$ is a vector of coefficients for these independent variables. Although the logistic transformation of the data adds an element of non-

\footnotetext{
${ }^{5}$ We note the likelihood of measurement problems in Polity (e.g., Gleditsch \& Ward, 1997). Because it is an additive index, there is less possibility of error at extremes of the scale than in the middle. It is difficult to overcome this problem based on the polity component factors (e.g., Werner's [2000] alternative scale suffers from similar problems). This introduces a bias against the regime similarity hypothesis because truly similar regimes are measured with increasing noise towards the middle of the scale.
} 
linearity to the model (and produces meaningful probabilities in the range from 0 to 1 ), the logodds are still a linear function of the input variables.

We follow Russett \& Oneal (2001) in using a general estimating equation (GEE) to implement time-series cross-sectional logit with semi-robust standard errors, controlling for firstorder serial correlation. Natural (or restricted) cubic splines (Beck, Katz, \& Tucker 1998) produce very similar results, with slightly lower levels of significance for the variables trade dependence, IGOs, distance, and parity, but no changes in sign or general significance at at least the $90 \%$ level.

As a complement to logit, we use support vector machines for much the same reason that others have suggested using artificial neural networks: the method is 'especially suitable to the interactive, non-linear, and contingent relations across the variables that may trigger militarized interstate disputes' (Lagazio \& Russett, 2004: 28-29; see also Beck, King, \& Zeng 2000; 2004). SVMs have a number of advantages over ANNs including an ability to avoid local minima and less demanding computational complexity (Cristianini \& Shawe-Taylor, 2000). They have been shown to perform as well as, or better than, ANNs (or logit) in a wide range of 'toy' and realworld applications (Schölkopf \& Smola, 2002). There is also a growing body of work which employs SVMs in financial economics (e.g., Dikkers \& Rothkrantz, 2005; Chalup \& Mitschele, forthcoming).

Here we can provide only a brief description of SVMs as used in this study. For more thorough introductory treatments, which have inspired the present overview, see Vapnik (1995), Burges (1998), Cristianini \& Shawe-Taylor (2000), Schölkopf \& Smola (2002), Mika et al. (2004), Bishop (2006). 
In general terms, SVMs seek a function $f: X \rightarrow Y$ from an input space $X$ (e.g. $X=\mathbb{R}^{n}$ )

to an output space, which in the case of two-class (binary) classification can be $Y=\{-1,1\}$. In the typical supervised learning paradigm only a sample set $Z=\left\{\left(x_{i}, y_{i}\right) \in X \times Y ; i=1, \ldots, m\right\}$ is given and the task is to find an $f$ which generalizes well to other examples outside $Z$. If $f$ is too simple it may underfit the data, and if $f$ is too complex it may overfit the data. A measure of the complexity or flexibility of a function class $F$ is the Vapnik-Chervonenkis dimension. The driving theoretical principle behind SVMs is called structural risk minimization (SRM) (Cortes \& Vapnik, 1995). It is based on a theoretical result which states that in a probabilistic sense the generalization error rate has an upper bound which is given by the training error and a term which depends on the Vapnik-Chervonenkis (1974) dimension (Cristianini \& Shawe-Taylor, 2000). SVMs can be seen as an approximation of SRM to find a function class $F$ and the function $f \in F$ such that the bound on the generalization error rate is minimized. The theory behind SVMs copes well with issues such as overfitting or the curse of dimensionality.

\section{Figure 2 here.}

Among the most basic SVMs in practical applications are maximum margin classifiers. Their aim is to find among many possible linear hyperplanes (Figure 2(a)) one which is able to separate two linearly separable point sets as well as possible. The margin is the smallest Euclidean distance between the separating hyperplane and the given training points $x_{i}, i=1, \ldots, m$ (cf. Figure 2(b)). The idea of SVMs is to find the separating hyperplane for which the margin of separation is maximized. Three situations are addressed: 
(I) The training data are linearly separable (Figure 2(b)).

(II) There may be outliers and noise in the data (Figure 2(c)).

(III) The data are by their nature not linearly separable and a non-linear decision boundary is required (Figure 3).

In the linear situation (I), by definition, there exist parameters $w \in \mathbb{R}^{n}$ and $b \in \mathbb{R}$ such that the hyperplane classifier $f(x)=\operatorname{sign}\left(w^{T} x_{i}+b\right)$ correctly separates the two classes. ${ }^{6}$ This can be summarized by the condition

$$
y_{i}\left(w^{T} x_{i}+b\right) \geq 1, i=1, \ldots, m
$$

which means $f\left(x_{i}\right) \geq 1$ for one class of examples and $f\left(x_{i}\right) \leq-1$ for the other class. The points on the margin boundaries are $f\left(x_{i}\right)= \pm 1$, and $f\left(x_{i}\right)=0$ would be points on the hyperplane.

The classical SVM algorithm is based on convex optimization theory and includes the following steps: Formulate the task as a quadratic programming problem in primal weight space; Establish the Lagrange function; Use the conditions of optimality; Solve the problem in the dual space of Lagrange multipliers (the non-zero Lagrange multipliers finally identify the support vectors). Technical details about this procedure are available in almost all standard texts on SVMs.

The primal optimization problem is to optimize the margin which corresponds to minimizing the weight vector, i.e. $w^{T} w$, subject to condition (2). The resulting linear SVM is

\footnotetext{
6. In SVM notation, 'sign' refers to the positive or negative sign of the function.
} 


$$
f(x)=\operatorname{sign}\left(\sum_{i \cong S V} \alpha_{i} y_{i} x_{i}^{T} x+b\right)
$$

which takes the sum over indices corresponding to support vectors, i.e. non-zero Lagrange multipliers.

The procedure for case II is very similar. The constraints change to

$$
y_{i}\left(w^{T} x_{i}+b\right) \geq 1-\xi_{i}
$$

where $\xi_{i}>0$ are slack variables (Figure 2(c)) which can take exceptions and outliers into account (Cortes \& Vapnik, 1995).

Figure 3 here.

Non-linear support vector machines (Boser et al., 1992) make use of Mercer's theorem (1909) which implies that if $x_{1}, \ldots, x_{m} \in \mathbb{R}^{n}$ are the input vectors and $k: \mathbb{R}^{n} \times \mathbb{R}^{n} \rightarrow \mathbb{R}$ is a positive semi-definite kernel function, then there exists a feature mapping $\phi: \mathbb{R}^{n} \rightarrow \mathbf{F}$ from the input space $\mathbb{R}^{n}$ to a high-dimensional feature space $\mathbf{F}$ (a Hilbert space) such that the kernel can be written as a dot product

$$
k\left(x_{i}, x_{j}\right)=\phi\left(x_{i}\right)^{\mathrm{T}} \phi\left(x_{j}\right)
$$


for all $i, j \in\{1, \ldots, m\}$. This implies that the kernel is a similarity measure between feature vectors. The procedure of finding a representation of an algorithm where feature vectors only occur as dot products $\phi\left(x_{i}\right)^{\mathrm{T}} \phi\left(x_{j}\right)$, so that these can be replaced by kernel values $k\left(x_{i}, x_{j}\right)$, is called the 'kernel trick' (Schölkopf \& Smola, 2002). This implies that for all calculations necessary for non-linear SVMs, the feature vectors $\phi\left(x_{i}\right) \in \mathbf{F}, i=1, \ldots, m$ do not need to be calculated explicitly and only occur implicitly within the kernel. The algorithmic procedure for the nonlinear case III is mostly analogous to case II. After substituting $x_{i}$ with $\phi\left(x_{i}\right)$ the constraints for the non-linear case become

$$
y_{i}\left(w^{T} \phi\left(x_{i}\right)+b\right) \geq 1-\xi_{i}
$$

In the dual representation of the task the kernel trick can be applied and the final support vector machine is

$$
f(x)=\operatorname{sign}\left(\sum_{i \cong S V} \alpha_{i} y_{i} k\left(x_{i}, x\right)+b\right)
$$

This means the non-linear SVM algorithm implicitly via $\phi$ maps all training data into a high dimensional feature space $\mathbf{F}$ where the data become linearly separable so that a linear SVM can be calculated. The linear hyperplane in feature space (Figure 2(b\&c)) then induces a non-linear separating decision surface in input space (Figure 3).

One of the core model selection parameters for non-linear SVMs is the type of kernel function. Among the most commonly used kernels is the radial basis function (RBF) kernel 


$$
k(x, y)=\exp \left(-\gamma\|x-y\|^{2}\right)
$$

where $\gamma$ is a free model selection parameter that controls the widths of the Gaussian or RBF functions. The present study employs C-SVMs with an RBF kernel for binary classification. In order to account for the rarity of international conflict (unbalanced output variable) weight balancing is applied (Raskutti \& Kowalczyk, 2004). This is a common approach, implemented, for example, in the LibSVM library (Chang \& Lin, 2001). To calculate probabilities we use Platt's (1999) method, although we do not argue that these are directly comparable to logit output.

As our discussion of the various hypotheses regarding dyadic regime type and international conflict reveals, theory does not provide a consensus about the appropriate functional form. Unlike statistical models such as logit, SVMs can deal with the potential (but unspecified) complexity of the data, explore a wide range of functional forms free from the bias introduced by variable specification, and discover which has more predictive power in a model. But there is a trade-off; powerful data exploration capabilities of SVMs correspond to dangers of over-fitting convoluted curves to finite data sets and mechanistically identifying correlations with no direction from the causal logic of plausible theory (but see Mika et al., 2004). While remaining cognizant of these dangers, we believe that theoretically informed SVM modeling can provide a powerful complement to more traditional statistical methods. This is especially so when there are several plausible functional forms, within a complex and interactive environment. We use out-of-sample testing to guard against over-fitting (de Marchi, Gelpi, \& Grynaviski, 
2004). We 'train' logit and SVM models on the same randomly selected $50 \%$ of the data, then test them on the remaining $50 \%$.

\section{ROC curves}

We use receiver operating characteristic (ROC) out-of sample tests to assess model fit for both logit and SVM. ROC tests evaluate overall predictive performance. Instead of specifying a random threshold (e.g., .5) as the cut-off for categorization, ROC curves consider the trade-off in true positives, true negatives, false positives, and false negatives across all possible predictive thresholds, and thus provide a general metric for comparing model performance. ROC analysis plots the true positive rate on the $y$-axis and the false positive rate on the x-axis. An especially useful indicator is the area under the ROC curve (AUC), which equals the probability that a model will correctly classify a randomly chosen positive outcome relative to a randomly chosen negative outcome (Fawcett, 2004). An AUC of .5 indicates prediction as well as chance, an AUC of 1.0 indicates perfect prediction.

\section{Data}

When choosing which variables to include, we take our lead from the democratic peace literature (e.g., Russett \& Oneal, 2001). A number of studies find no significant effect of alliances on conflict (e.g., Gibler, 2000; Maoz, 2000). We also found no significant effect, and so dropped the variable. Another questionable variable is dyadic trade. Recent studies (Goenner, 2004; Keshk, Pollins, \& Reuveny, 2004) cast doubt on the causal effect of trade on conflict. However, given the recency of these findings and the strong arguments in liberal theory regarding economic interdependence, we report results with and without trade. For the remaining variables, 
we use the latest available data and follow common practices in the literature (our measure for major power dyads is somewhat different, as discussed below) ${ }^{7}$

\section{Politically relevant dyads}

The unit of analysis is the dyad year, and the domain is 'politically-relevant' dyads: states that are contiguous on land or within 400 miles over water, as well as pairs containing at least one major power. Our definition of political relevance captures $78 \%$ of all initiations of fatal disputes, but uses only $13 \%$ of possible dyadic combinations. Using all possible pairings would create over 600,000 dyad-years, a data set requiring more computing power than we had available for SVM analysis.

\section{Dependent variable / outcome}

Fatal Disputes is a binary variable coded " 1 " if a dyad experienced the outbreak of a Militarized Interstate Dispute (MID) in a given year which at some point claimed at least one combatant's life according to the Correlates of War (COW) data. This choice of outcome variable has the advantages of eliminating less consequential disputes (e.g., verbal threats) and of being more common than the standard measure of 'war' involving at least 1000 battle deaths. We follow recent work on the liberal peace (e.g., Mousseau, Hegre, \& Oneal, 2003) in choosing this indicator of serious international conflict. When two or more disputes initiate in a year, the highest intensity dispute is used. Dyad years with ongoing disputes are dropped. Joiner dyads are included.

\footnotetext{
${ }^{7}$. All data are generated using EUGene software, version 3.040 except as otherwise noted (Bennett \& Stam 2003).
} 


\section{Independent variables / inputs}

Data from the Polity IV project (Marshall \& Jaggers, 2002) are used to create a regime-type indicator for each state in the dyad. This is done by subtracting the 'Autocracy' from the 'Democracy' scale to form a general index ranging from -10 for fully autocratic/authoritarian regimes to +10 for fully democratic regimes. The Polity index is a commonly used indicator of regime type, has broad coverage, and is generally at least as reliable and valid as any other existing indicator, although of course not without shortcomings (Munck \& Verkuilen, 2002; Gleditsch \& Ward, 1997).

The creation of various indicators of dyadic regime type and political distance has been discussed in detail above. All regime type measures used in the logit analysis are normalized to a scale of $0-1$ for ease of interpretation. We emphasize that SVM models require no assumptions about functional form and thus the raw polity scores are the inputs.

Our indicators of economic interdependence for a dyad use total dyadic trade divided by each state's GDP. Trade dependence is given by the lower interdependence ratio among the states in the dyad (version 4.1 of Gleditsch's [2002] trade data). For the period before 1948, when Gleditsch's data start, we use trade data from Russett \& Oneal (2001).

Membership in international governmental organizations (IGOs) is measured by the total number of IGOs that both dyad members belong to. We use data updated and corrected by Pevehouse, Nordstrom, \& Warnke (2003). Since the data contain observations at five-year intervals up to 1965 , values are filled in until 1965 by projecting summed memberships forward for 4 years. 
The contiguity variable is coded ' 1 ' if two states share a land border, ' 0 ' otherwise. Contiguity across small distances of water is not allowed, in order to provide the clearest possible distinction between this variable and the distance measure.

The Major Powers variable is coded ' 1 ' if both states in a dyad are major powers (as coded by COW), ' 0 ' otherwise. This measure is somewhat different from other studies. Our analysis has shown that dyads containing only one major power (the standard measure) are no more likely to experience conflict than dyads containing two minor powers, once a control for major-major dyads is included.

The distance variable measures miles between capital cities, calculated using the 'great circle' method (Bennett \& Stam, 2003: 15).

The power balance or parity measure is based on the COW composite index of national capabilities (CINC) which includes military personnel and expenditures, energy production, iron and steel production, urban and total population. The ratio of the stronger to the weaker state is taken for each dyad, so that the indicator theoretically ranges from ' 0 ' (complete imbalance) to '1' (perfect power parity).

The natural $\log$ of interdependence, IGO memberships, distance, and parity is used in the logit analysis (adding 1 to any variable for which the lowest value is 0 ). Fatal dispute initiation at $t+1$ is used to allow for a one-year lag in the causal effects of the independent variables in both logit and SVM models.

\section{Results}

In this section we address the sensitivity of logit results under different specifications, the implications of SVM models for assumptions about the functional form of regime type, and the 
goodness of fit of logit and SVM. The purpose of presenting a variety of logit results is to demonstrate their indeterminate nature.

The logit models presented in Table I illustrate the potential for inconsistent but statistically significant results. Different specifications support different interpretations. The models' out-of-sample predictive ability ranges from AUC .74 to .78. General support for the democratic peace is found in all models except Model 3 (the joint democracy dummy variable's effect is insignificant). However, all models can also be interpreted as supporting (or not contradicting) the regime similarity hypothesis, especially models 3 and 4. Regime rationality fares nearly as well, strongly supported by models 5 and 6 .

\section{Table I here}

A researcher might be justified in choosing any one of the three contending theoretical perspectives based on these results. However, alternative specifications seem to undermine any given choice, as well. Table II illustrates this. Democratic peace is not supported in models 7, 8, or $10 .^{8}$ Regime similarity fares badly in Model 9 (due to the insignificance of joint anocracy). Model 10 especially undermines the regime rationality hypotheses. Equally powerful out-ofsample prediction can be found to support each perspective (AUC around .77 or .78), but clearly

\footnotetext{
${ }^{8}$. When more restricted indicators of political similarity (1-point difference or exact equality) are used in model 10 , the categorical joint democracy and joint autocracy indicators tend to gain significance, while political similarity loses significance. While interpretation of such effects is difficult, our point that logit results are sensitive to variable specification is reinforced.
} 
the functional forms of dyadic regime type actually modeled are substantially different, as illustrated by the surface graphs for high-conflict scenarios ${ }^{9}$ for models $1,3,5,8$, and 9 .

\section{Table II here}

We believe that in such a situation, when theories apparently capture part of reality, but our methods have trouble distinguishing between theoretical implications, machine learning techniques have much to offer the social sciences. SVM estimation can suggest the most plausible functional form for dyadic regime type, controlling for independent and interactive effects of other factors while avoiding the restrictive and misleading assumptions of logit.

We examine the SVM results using three-way surface graphs with each dyad member's regime type along the $\mathrm{x}$ and $\mathrm{y}$ axes. Figure 4 presents a graph for the $20^{\text {th }}$ percentile of highconflict scenarios, holding the other variables in the model constant. This is juxtaposed with logit results for the same data held at the same values, including both political distance and joint democracy variables as in Model 3 (highest AUC in Table I). The inputs for regime type in the SVM model were simply the raw polity scores for each member of a dyad. The relationship between them and the outbreak of deadly conflict shown in Figure 4 was thus 'discovered' by the SVM without any bias introduced by coding decisions favoring a given theory (e.g., weak-link, political distance, categorical regime type, etc.).

\section{Figure 4 here}

\footnotetext{
${ }^{9}$ We simulate a scenario in which the probability of conflict is high by holding other variables at their $20^{\text {th }}$ percentile value in the direction of conflict. These values are 9 joint IGO memberships, .000006 dependency, not contiguous on land, not a major-major dyad, 635 miles between capitals, and a .25 parity score.
} 
Nevertheless the SVM results are readily interpretable in terms of extant theory. Surface graphs can help us ascertain the general functional form for the relationship between conflict and regime type, across all possible dyadic regime pairings, by showing the variation in conflict as each state's type ranges from authoritarian to democratic. Generalization can be extended to another dimension by varying the values taken by other variables. The graphs in Figure 5 hold other variables at five sets of values, ranging from very low probability of conflict $\left(5^{\text {th }}\right.$ percentile) to very high $\left(5^{\text {th }}\right.$ percentile). The SVM results, shown from front and side perspectives (first two columns, on the left), are juxtaposed with the comparatively rigid logit results (third column, on the right). Despite the different functional forms, there is little difference in overall out-of-sample performance: ROC AUC is only slightly lower for SVM (.7689) than for the best logit models.

Our basic interpretation of the functional form from SVM analysis is that democratic peace and regime similarity have some effects across all regime-type combinations in most circumstances. This is clear from the steep downward slope ${ }^{10}$ towards fully democratic dyads in Figure $5(\mathrm{a}-\mathrm{e})$, and the surface concavity of Figure $5(\mathrm{~b}-\mathrm{e})$. Jointly authoritarian regimes are exceptionally conflictual, as expected by incremental interpretations of democratic peace, but this effect dissipates as conflict becomes more likely and appears negative in high conflict scenarios, as expected by our regime rationality conjectures (Figure 5(a\&b)). And when the other variables in the model make conflict very likely (Figure 5(a)), the functional form changes

\footnotetext{
${ }^{10}$. This slope might imply that a state's change toward democracy over time, or democratization, also corresponds with a reduction in the likelihood of war (e.g., Ward \& Gleditsch, 1998); however we caution against such an interpretation since we do not model regime change over time explicitly; the results can only be suggestive of such a process. We also note the slope for SVM output is non-monotonic in Figure $5(\mathrm{~b})$.
} 
radically: joint democracy is now the dominant effect. There is also some indication that jointly authoritarian dyads are more pacific; but the pacific regime similarity effect is not evident, rather it is reversed!

\section{Figure 5 here}

It is clear that the computational complexity and flexibility of SVMs allows this moving functional form to emerge in a way logit (Figure 5, third column) does not. These new clues allow us to make a preliminary attempt at a coherent explanation of the general relationship. We recognize that further analysis and confirmation are necessary; but as a first cut, we propose an explanation based on varying conditions of risk. When risks are low (i.e., the probability of war is low based on other factors), then all non-democratic dyads will tend to be subject to bluffing and foreign policy belligerence for strategic advantage. Democracies will be constrained due to their relative transparency and inability to bluff. As conflict becomes a real possibility, leaders realize the risks of their posturing, and those that can will reign in their bluster. These will be leaders in solidly authoritarian dyads for the reasons outlined in the regime rationality discussion above. They control the state apparatus and do not face serious leadership challenges from other sub-national factions.

Throughout these degrees of risk the factor of regime similarity points to states simply having less to fight about, as outlined by Werner. However, when the non-regime factors in the model make the probability of war very high, obviously even similar regimes have other issues at stake that they might fight over. The regime similarity factor disappears when other issues intrude (e.g., a security dilemma arising from contiguity and power parity). In such 
circumstances, it is largely joint democracy which matters. Credible crisis signaling as well as normative and structural constraints come into play. Other dyads lack the tools to avoid the costs of war in the most dangerous of dyadic combinations, with a limited exception for 'rational' jointly authoritarian dyads (Figure 5(a)).

This leads to strong, but also qualified, support for democratic peace theories. The democratic peace finds its best empirical support in a small corner of the data on international conflict. But the dyads inhabiting that corner are the most likely to go to war based on their other characteristics.

\section{Conclusions}

We have sketched a general explanation of the relationship between regime type and war which combines the logic of each of the three schools noted above, given the SVM and logit results. Each school finds some support using logit because each is indeed a part of the explanation. But the interactive and non-linear dynamics only become apparent using a more flexible and sensitive instrument, SVMs.

The advantages of SVM modeling seem clear in light of these results. The most likely functional form for regime type changes based on the degree to which other variables predict war or peace. Our SVM results suggest that the dynamics of regime type and conflict are similar for

the majority of dyads which inhabit the range between the $20^{\text {th }}$ percentiles for high and low conflict: regime similarity and joint democracy are the factors at work, but their substantive effects are minor. For the small sub-set of dyads with high potential for deadly conflict, regime rationality gains importance, and regime similarity loses importance as other factors make war more probable. The results suggest that models of international conflict excluding distinct 
indicators for political similarity, joint democracy, and joint authoritarianism are probably misspecified and likely suffer from omitted variable bias. Even then, important non-linear interactions would need to be included.

Such complex interaction effects between dyadic regime type and other factors in the model would be exceedingly difficult to include in a standard logit specification, especially without specific theoretical guidance. But such implications have not emerged clearly from formal models of strategic bargaining and war, or other theorizing. SVM methods, however, give strong reason to suspect democratic peace, regime similarity, and regime rationality are each important aspects of a general understanding of regime type and war, and that their relative importance is conditioned on the force of other factors pushing a dyad into conflict.

\section{Appendix}

Interval measure of joint democracy.

Table A here. 


\section{Figures}

Figure 1. Hypothesized effect of regime type on the probability of conflict.

a. Categorical Democratic Peace

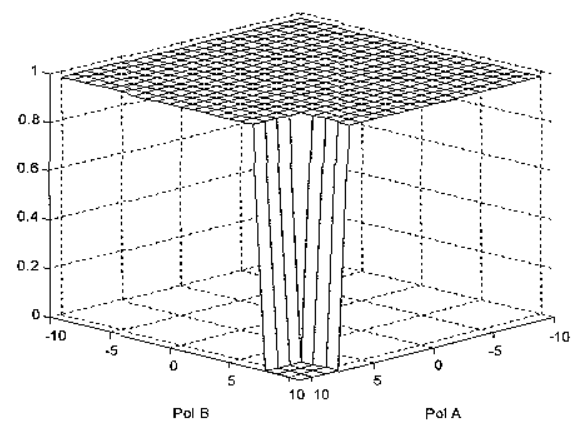

b. Interval Democratic Peace

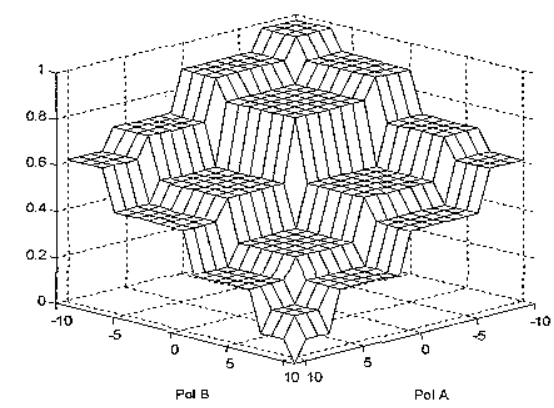

c. Regime Similarity (Political Distance)

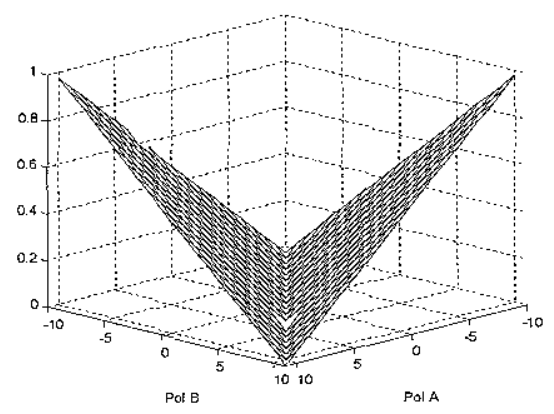

d. Regime Rationality

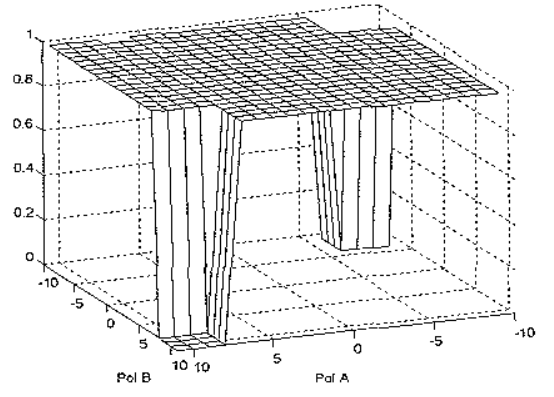


Figure 2.

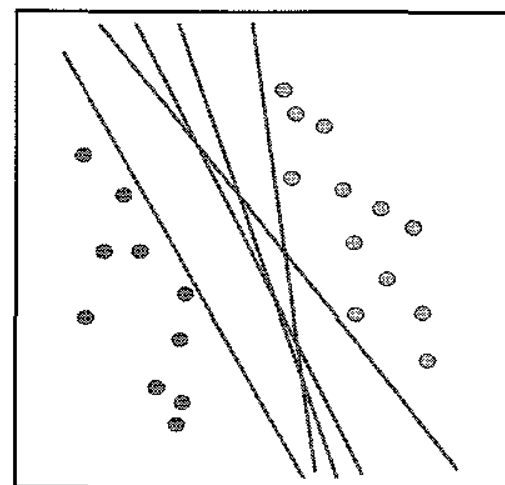

a.

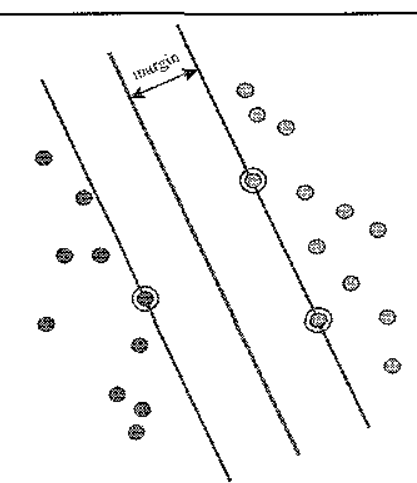

b.

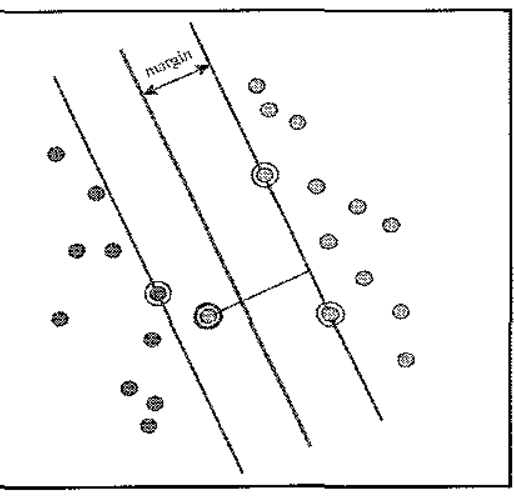

c.

(a) Examples of separating hyperplanes; (b) Separating hyperplane with maximum margin obtained with a linear SVM. The support vectors are the encircled points on the margin boundaries; (c) Linear SVM with outlier within the margin boundaries which will be penalized by a slack variable $\xi$. 
Figure 3.

Non-linear decision surface with support vectors on the margin boundaries.

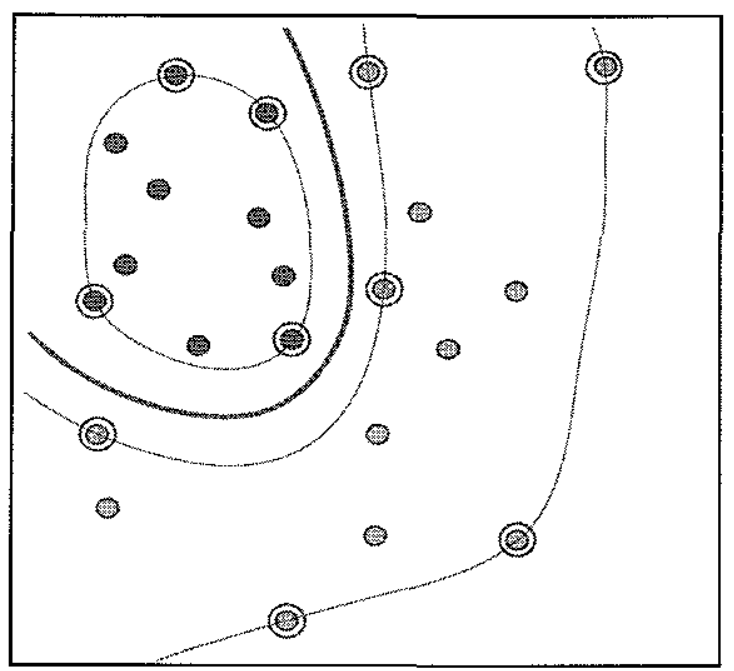


Figure 4.

Logit (Model 3)

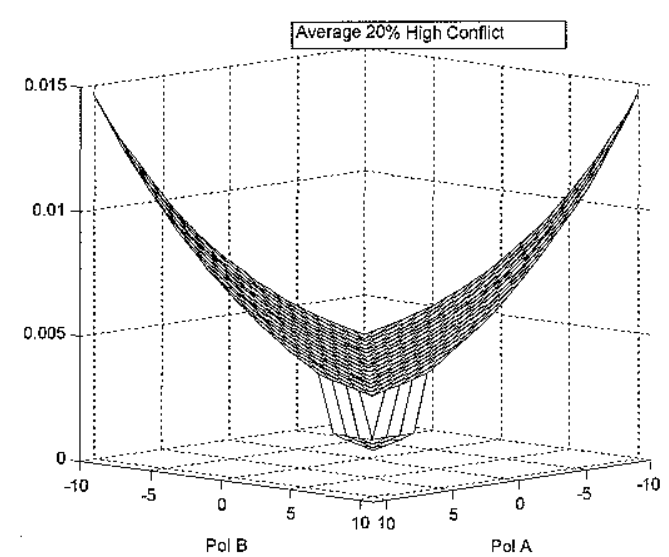

$\mathrm{AUC}=.7810$
SVM

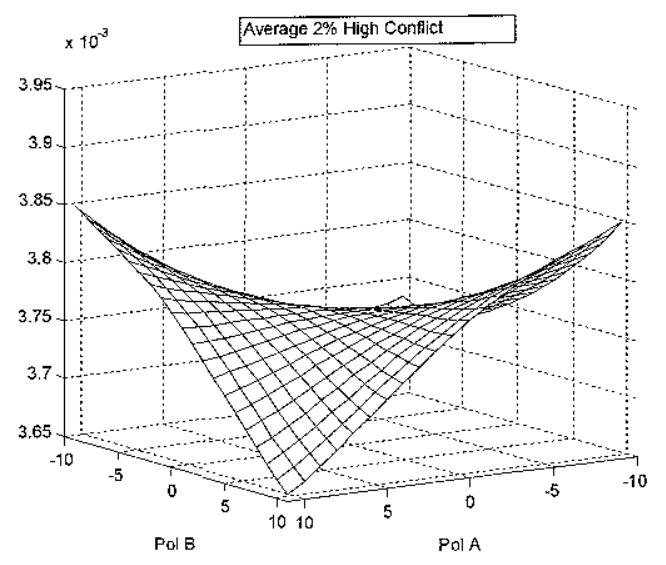

$\mathrm{AUC}=.7689$ 
Figure 5.

a. 5th Percentile High Conflict

SVM
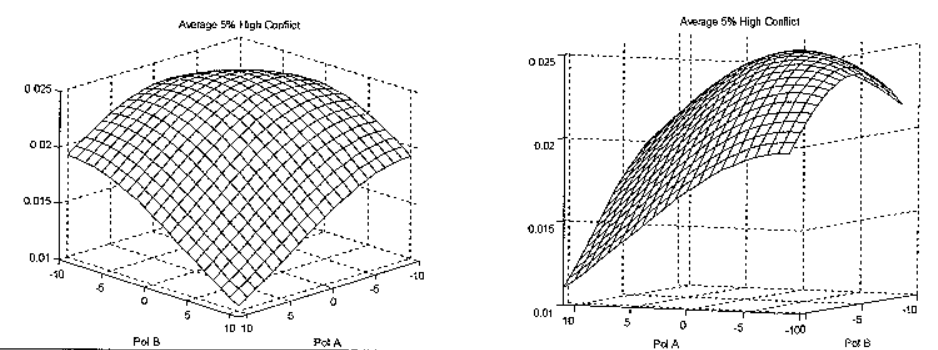

b. 20th Percentile High Conflict
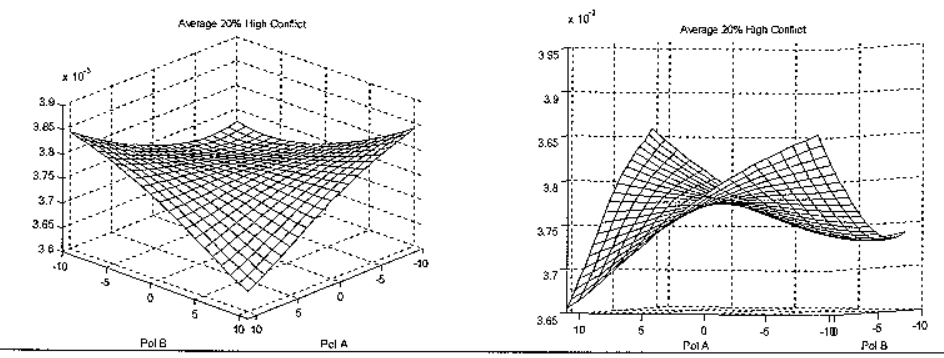

c. 50th Percentile
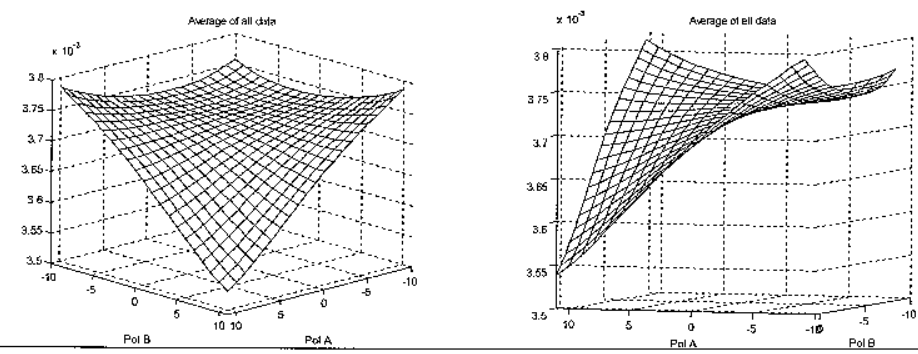

d. 20th Percentile Low Conflict
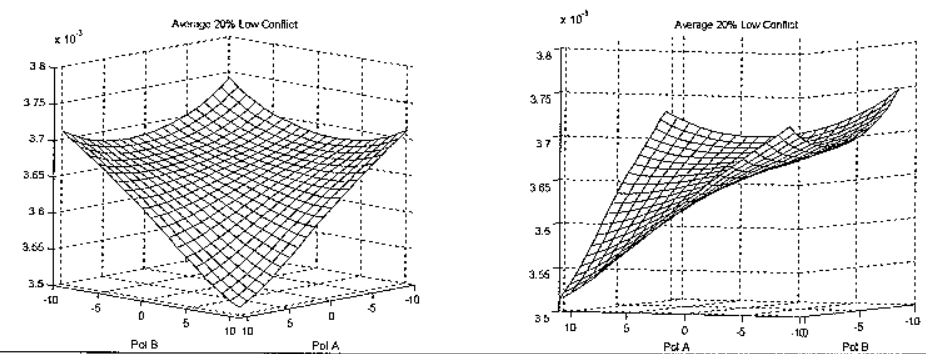

e. 5th Percentile Low Conflict
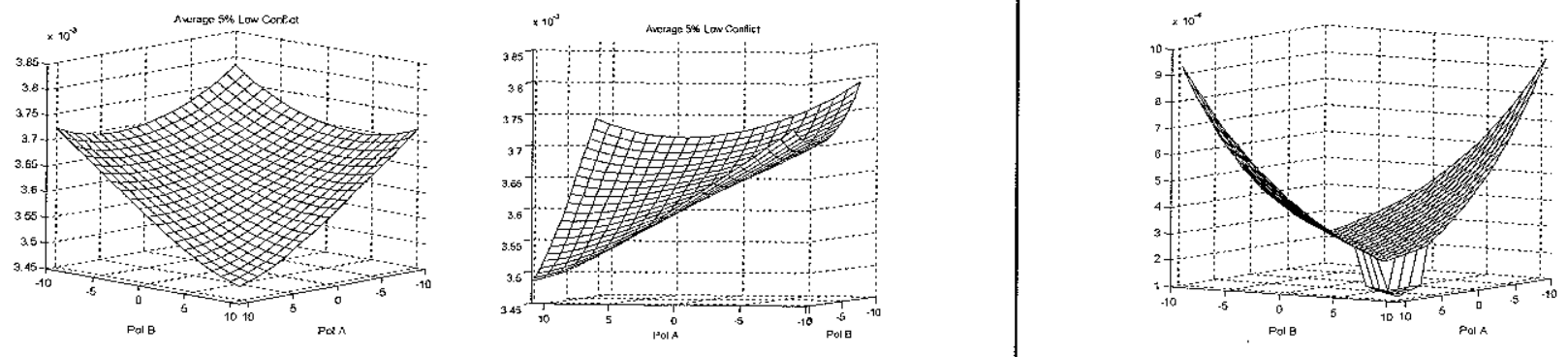
Table I.

Logit Estimation, Onset of Fatal Conflict, 1886-2000.

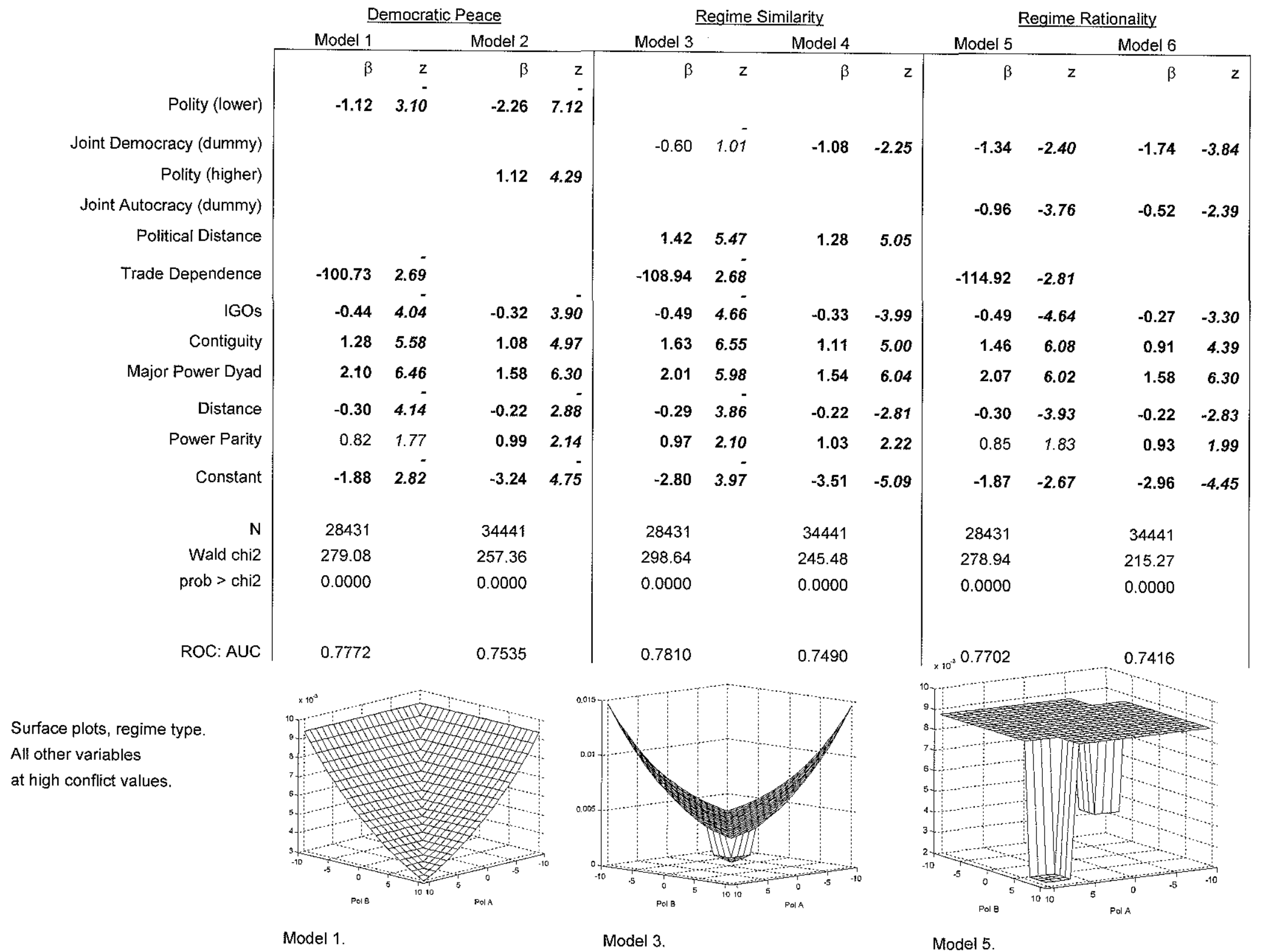


Tables.

Table II.

\section{Logit Estimation, Onset of Fatal Conflict, 1886-2000.}

\begin{tabular}{|c|c|c|c|c|c|c|c|c|}
\hline & & & Alte & native & ecification & & & \\
\hline & & & Model & & & & & \\
\hline & \multicolumn{2}{|l|}{ Model 7} & \multicolumn{2}{|l|}{8} & \multicolumn{2}{|c|}{ Model 9} & \multicolumn{2}{|l|}{ Model 10} \\
\hline & $\beta$ & z & $\beta$ & z & $\beta$ & $z$ & $\beta$ & $z$ \\
\hline Joint Democracy (interval) & -0.18 & 0.48 & & & & & & \\
\hline Joint Democracy (dummy) & & & -0.57 & 0.95 & -1.34 & 2.40 & -0.84 & -1.36 \\
\hline Joint Autocracy (dummy) & & & & & -0.96 & 3.77 & -0.50 & -1.52 \\
\hline Joint Anocracy (dummy) & & & & & -0.15 & 0.26 & & \\
\hline Political Similarity (dummy) & & & -0.86 & 4.18 & & & -0.58 & -2.18 \\
\hline Political Distance & 1.55 & 6.47 & & & & & & \\
\hline Trade Dependence & -112.08 & 2.72 & -112.93 & 2.89 & -114.96 & 2.81 & -114.87 & -2.88 \\
\hline IGOs & -0.50 & 4.77 & -0.50 & 4.69 & -0.49 & 4.64 & -0.50 & -4.73 \\
\hline Contiguity & 1.66 & 6.65 & 1.51 & 6.31 & 1,46 & 6.09 & 1.53 & 6.33 \\
\hline Major Power Dyad & 2.02 & 6.06 & 2.05 & 6.09 & 2.07 & 6.03 & 2.05 & 6.01 \\
\hline Distance & -0.29 & 3.82 & -0.30 & 4.08 & -0.30 & 3.93 & -0.30 & -3.98 \\
\hline Power Parity & 0.99 & 2.16 & 0.90 & 1.96 & 0.85 & 1.85 & 0.88 & 1.93 \\
\hline Constant & -2.84 & 4.04 & -1.77 & 2.59 & -1.87 & 2.67 & -1.79 & -2.57 \\
\hline $\mathrm{N}$ & 28431 & & 28431 & & 28431 & & 28431 & \\
\hline Wald chi2 & 308.96 & & 273.66 & & 279.47 & & 285.43 & \\
\hline prob $>$ chi 2 & 0.0000 & & 0.0000 & & 0.0000 & & 0.0000 & \\
\hline ROC: AUC & 0.7821 & & 0.7753 & & 0.7702 & & 0.7737 & \\
\hline
\end{tabular}

Surface plots, regime type. All other variables at high conflict values.

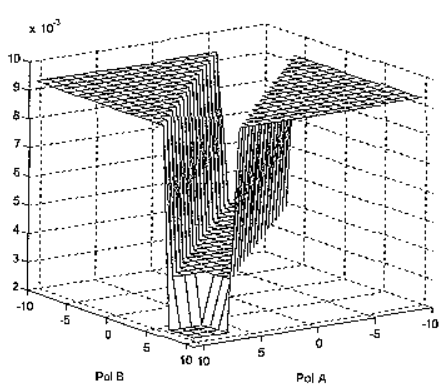

Model 8

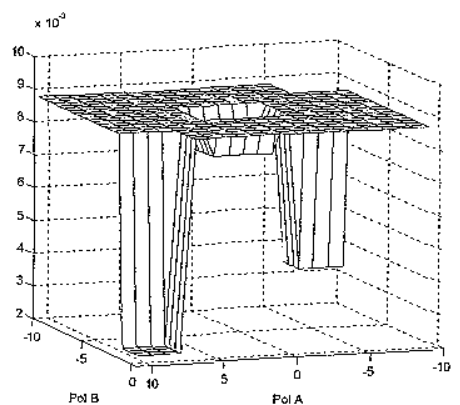

Model 9. 
Table A.

Interval measure of dyadic joint democracy

Joint democracy $\quad$\begin{tabular}{rrrr} 
stateA & stateB & dyad rank \\
10 & 10 & 11 \\
10 & $7-9$ & 10 \\
$7-9$ & $7-9$ & 9 \\
\hline $7-10$ & $0-6$ & 8 \\
$0-6$ & $0-6$ & 7 \\
$7-10$ & $-6-0$ & 6 \\
$0-6$ & $-6-0$ & 5 \\
$7-10$ & $-10--7$ & 4 \\
$0-6$ & $-10--7$ & 3 \\
\hline$-6-0$ & $-6-0$ & 2 \\
$-6-0$ & $-10--7$ & 1 \\
$-10-7$ & $-10--7$ & 0 \\
\hline
\end{tabular}




\section{References}

Beck, Nathaniel, Jonathan N. Katz, \& Richard Tucker, 1998. 'Taking Time Seriously: Timeseries-cross-section analysis with a binary dependent variable,' American Journal of Political Science 42(4): 1260-1288.

Beck, Nathianiel, Gary King, \& Langche Zeng, 2000. 'Improving Quantitative Studies of International Conflict,' American Political Science Review 94(1): 21-35.

Beck, Nathianiel, Gary King, \& Langche Zeng, 2004. 'Theory and Evidence in International Conflict: A response to de Marchi, Gelpi, and Grynaviski,' American Political Science Review 98(2): 379-389.

Bennett, D. Scott \& Allan Stam, 2003. EUGene: Expected utility generation and data management program. Documentation. V 3.03. http://www.eugenesoftware.org/.

Bishop, Christopher M., 2006. Pattern Recognition and Machine Learning. New York: Springer.

Boser, Bernhard, Isabelle Guyon, \& Vladimir N. Vapnik, 1992. 'A training algorithm for optimal margin classifiers,' in Fifth Annual Workshop on Computational Learning Theory. San Mateo, CA: Morgan Kaufmann (144-152).

Bueno de Mesquita, Bruce, James D. Morrow, Randolph M. Siverson, \& Alastair Smith, 1999. 'An Institutional Explanation of the Democratic Peace,' American Political Science Review 93(4): 791-807.

Burges, Christopher J. C., 1998. 'A tutorial on support vector machines for pattern recognition,' Data Mining and Knowledge Discovery 2(2): 121-167.

Cederman, Lars-Erik \& Mohan Penubarti Rao, 2001. 'Exploring the Dynamics of the Democratic Peace,' Journal of Conflict Resolution 45(6): 818-833.

Chalup, Stephan K. \& Andreas Mitschele, forthcoming. 'Kernel Methods in Finance,' in Detlef Seese, Christof Weinhardt, \& Frank Schlottmann, eds. IT and Finance: Handbook. Berlin: Springer-Verlag (1-34).

Chang, Chih-Chung \& Chih-Jen Lin, 2001. LIBSVM: a library for support vector machines. Software available at http://www.csie.ntu.edu.tw/ cjlin/libsvm/index.html.

Cortes, Corinna \& Vladimir Vapnik, 1995. 'Support Vector Networks'. Machine Learning, 20(3): 273-297.

Cristianini, Nello \& John Shawe-Taylor, 2000. An Introduction to Support Vector Machines and Other Kernel-based Learning Methods. Cambridge, U.K.: Cambridge University Press. 
de Marchi, Scott, Christopher Gelpi, \& Jeffrey D. Grynaviski, 2004. 'Untangling Neural Nets,' American Political Science Review 98(2): 371-378.

Dikkers, Harmen \& Leon Rothkrantz, 2005. 'Support vector machines in ordinal classification: An application to corporate credit scoring,' Neural Network World 15(6): 491-507.

Dixon, William, 1994. 'Democracy and the Peaceful Settlement of International Conflict,' American Political Science Review 88(1): 14-32.

Fawcett, Tom, 2004. 'ROC Graphs: Notes and practical considerations for researchers,' typescript, HP Laboratories (http://home.comcast.net/ tom.fawcett/public_html/articles/ROC101.pdf).

Fearon, James D., 1994. 'Domestic Political Audiences and the Escalation of International Disputes,' American Political Science Review 88(3): 577-92.

Fearon, James D., 1995. 'Rationalist Explanations for War', International Organization 49(3): $379-414$.

Fearon, James D., 1997. 'Signaling Foreign Policy Interests: Tying hands versus sinking costs,' Journal of Conflict Resolution 41(1): 68-90.

Fearon, James D., 1998. 'Domestic Politics, Foreign Policy, and Theories of International Relations,' Annual Review of Political Science 1: 289-313.

Gartzke, Erik, 1998. 'Kant We All Just Get Along? Opportunity, willingness, and the origins of the democratic peace,' American Journal of Political Science 42(1): 1-27.

Gibler, Douglas M., 2000. 'Alliances: Why some cause war and others cause peace,' in John A. Vasquez, ed. What Do We Know about War? Lanham, MA: Rowman and Littlefield $(145-164)$.

Gleditsch, Kristian S., 2002. 'Expanded Trade and GDP Data,' Journal of Conflict Resolution 46(5): 712-24 [version 4.1, http://dss.ucsd.edu/ kgledits/exptradegdp.html]

Gleditsch, Kristian S. \& Michael D. Ward, 1997. 'Double Take: A reexamination of democracy and autocracy in modern polities,' Journal of Conflict Resolution 42(3): 361-383.

Gleditsch, Nils Petter \& Håvard Hegre, 1997. 'Peace and Democracy: Three levels of analysis,' Journal of Conflict Resolution 41(2): 283-310.

Goenner, Cullen F., 2004. 'Uncertainty of the Liberal Peace,' Journal of Peace Research 41(5): 589-605. 
Keshk Omar M.G., Brian M. Pollins, \& Rafael Reuveny, 2004. 'Trade still follows the flag: The primacy of politics in a simultaneous model of interdependence and armed conflict,' Journal of Politics 66(4): 1155-1179.

Lagazio, Monica \& Bruce Russett, 2004. 'A Neural Network Analysis of Militarized Disputes, 1885-1992: Temporal stability and causal complexity,' in Paul F. Diehl, ed. The Scourge of War: New extensions on an old problem. Ann Arbor: University of Michigan Press (28-60).

Lai, Brian \& Dan Reiter, 2000. 'Democracy, Political Similarity, and International Alliances, 1816-1992,' Journal of Conflict Resolution 44(2): 203-227.

Lake, David A., 1992. 'Powerful Pacifists: Democratic states and war,' American Political Science Review 86(1): 24-37.

Maoz, Zeev, 2000. 'Alliances: The street gangs of world politics,' in John A. Vasquez, ed. What Do We Know about War? Lanham, MA: Rowman and Littlefield (111-144).

Maoz, Zeev \& Nasrin Abdolali, 1989. 'Regime Types and International Conflict, 1816-1976,' Journal of Conflict Resolution 33(1): 3-35.

Maoz, Zeev \& Bruce Russett, 1993. 'Normative and Structural Causes of Democratic Peace, 1946-1986,' American Political Science Review 87(3): 624-638.

Marshall, Monty G. \& Keith Jaggers, 2002. Polity IV Project: Political Regime Characteristics and Transitions, 1800-2002. http://www.cidcm.umd.edu/inscr/polity/index.htm.

Mercer, James, 1909. 'Functions of positive and negative type, and their connection with the theory of integral equations,' Transactions of the London Philosophical Society (A) 209: 415446.

Mika, Sebastian, Christin Schafer, Pavel Laskov, David Tax, \& Klaus-Robert Muller, 2004. 'Support vector machines,' in James E. Gentle, Wolfgang Hardle, Yuichi Mori, eds., Handbook of Computational Statistics: Concepts and methods. Berlin: Springer-Verlag (841-876).

Mousseau, Michael, 1998. 'Democracy and Compromise in Militarized Interstate Disputes, 1816-1992,' Journal of Conflict Resolution 42(2): 210-230.

Mousseau, Michael, Håvard Hegre, \& John R. Oneal, 2003. 'How the wealth of nations conditions the liberal peace,' European Journal of International Relations 9(2): 277-314.

Munck, Gerardo L. \& Jay Verkuilen, 2002. 'Conceptualizing and Measuring Democracy: Evaluating alternative indices,' Comparative Political Studies 35(1): 5-34.

Peceny, Mark, Caroline C. Beer with Shannon Sanchez-Terry, 2002. 'Dictatorial Peace?' American Political Science Review 96(1): 15-26. 
Pevehouse, Jon, Timothy Nordstrom, \& Kevin Warnke, 2003. 'Intergovernmental Organizations, 1815-2000: A New Correlates of War Data Set,' Version 2.1, available from the COW2 website [http://cow2.la.psu.edu/].

Platt, John C., 1999. 'Probabalistic Outputs for Support Vector Machines and Comparisons to regularized Likelihood Methods,' [accessible at: http://research/microsoft.com/ jplatt].

Raskutti, Bhavani \& Adam Kowalczyk, 2004. 'Extreme re-balancing for svms: a case study. SIGKDD,' Explorations 6(1): 60-69.

Reiter, Dan, 2003. 'Exploring the Bargaining Model of War,' Perspectives on Politics 1(1): 2743.

Reuveny, Rafael \& Quan Li, 2003. 'The Joint-Democracy-Dydadic Conflict Nexus: A simultaneous equations model,' International Studies Quarterly 47(3): 325-346.

Russett, Bruce \& John Oneal, 2001. Triangulating Peace: Democracy, Interdependence, and International Organizations. New York: W.W. Norton.

Russett, Bruce, John R. Oneal, \& David R. Davis, 1998. 'The Third Leg of the Kantian Tripod for Peace: International organizations and militarized disputes, 1950-85,' International Organization 52(3): 441-467.

Schölkopf, Bernhard \& Alexander J. Smola, 2002. Learning with Kernels: Support Vector Machines, Regularization, Optimization, and Beyond. Cambridge, MA: MIT Press.

Schultz, Kenneth A., 1999. 'Do Democratic Institutions Constrain or Inform? Contrasting two institutional perspectives on democracy and war,' International Organization 53(2): 233-266.

Signorino, Curtis S., 1999. 'Strategic Interaction and the Statistical Analysis of International Conflict,'American Political Science Review 93(2): 279-297.

Signorino, Curtis S., 2003. 'Structure and uncertainty in discrete choice models,' Political Analysis 11(4): 316-344.

Signorino, Curtis S. \& Kuzey Yilmaz, 2003. 'Strategic Misspecification in Regression Models,' American Journal of Political Science 47(3): 551-566.

Vapnik, Vladimir \& Alexey Chervonenkis, 1974. Theory of Pattern Recognition [in Russian]. Moscow: Nauka.

Vapnik, Vladimir N., 1995. The Nature of Statistical Learning Theory. New York: Springer Verlag.

Ward, Michael D. \& Kristian S. Gleditsch, 1998. 'Democratizing for Peace,' American Political Science Review 92(1): 51-61. 
Werner, Suzanne, 2000. 'The Effects of Political Similarity on the Onset of Militarized Disputes, 1816-1985.' Political Research Quarterly 53(2): 343-374. 